\title{
LEITURA E LETRAMENTO: UMA PROPOSTA DE ATIVIDADE NAS AULAS DE INGLÊS
}

\author{
S. C. SUCCI* \\ Pontifícia Universidade Católica de São Paulo \\ simone_succi@hotmail.com*
}

Artigo submetido em 02/12/2018 e aceito em 13/05/2019

DOI: $10.15628 /$ holos.2019.8003

\section{RESUMO}

Este estudo pretende trazer algumas reflexões acerca dos objetivos do ensino de Língua Inglesa na educação básica e suas implicações no contexto da escola pública. De modo específico apresenta, discute e propõe uma possibilidade de desenvolvimento para uma atividade inserida no material didático Caderno do Aluno (2009) do Ensino Médio. Tal proposta didática está baseada nas Diretrizes do Currículo de Língua Estrangeira Moderna do estado de São Paulo (LEM, 2008) e em consonância com as Orientações Curriculares para o Ensino Médio (OCEM,
2006). Esses documentos abordam que o ensino de Língua Inglesa deve privilegiar atividades que promovam o letramento e as práticas de leitura a fim de promover a participação do aluno em diferentes contextos sociais que envolvem a leitura e a escrita na língua -alvo. Isso significa que a aula de língua inglesa deve criar condições para que o aluno se engaje em atividades que demandam o uso da língua a partir de temas relevantes ao seu contexto social por meio de gêneros textuais diversos.

PALAVRAS-CHAVE: Língua inglesa, Escola pública, Leitura, Letramento.

\section{READING AND LITERACY: A PROPOSAL OF ACTIVITY IN ENGLISH CLASSES}

\begin{abstract}
This study intends to bring some reflections about the objectives of English language teaching in basic education and its implications in the context of the public school. Specifically presents, discusses and proposes a possibility of development for an activity inserted in the didactic material Student Notebook (2009) of High School. This didactic proposal is based on the Guidelines of the Modern Foreign Language Curriculum of the state of São Paulo (LEM, 2008) and in line with the Curricular Orientations for High School (OCEM, 2006). These
\end{abstract}

documents suggest that English language teaching should focus on activities that promote literacy and reading practices to promote student participation in different social contexts involving reading and writing in the target language. This means that the English language class should create conditions for the student to engage in activities that demand the use of the language from themes relevant to their social context through various textual genres.

KEYWORDS: English language, Public school, Reading, Literacy. 


\section{INTRODUÇÃO}

Não são raros os estudos e pesquisas que versam sobre a precária qualidade do ensino de língua estrangeira nas escolas regulares e sobre o descrédito dos pais, alunos, professores e gestores educacionais em relação à possibilidade de ocorrer um aprendizado efetivo de LE (Língua Estrangeira) /LI (Língua Inglesa) durante a educação básica. Essa situação de dificuldade de recursos estruturais e humanos, particularmente, na escola pública já havia sido alertada por Cox e AssisPeterson (2008, p.10), ao afirmarem que na escola pública

O cenário é de malogro: lugar de alunos que não aprendem, de professores que não sabem a língua que ensinam, de pais que não se preocupam com a educação dos filhos e de metodologias que não funcionam. Nela, o ensino de Inglês é uma história de faz de conta, encenada por professores invisíveis.

As justificativas para essa mazela recaem sobre a falta de materiais didáticos, de recursos estruturais e tecnológicos, a formação deficiente dos professores e seus baixos salários, as poucas aulas de Inglês na carga horária semanal e as salas de aula com elevado número de alunos. Somado a esses fatores há, também, o longo período entre 1961 a 1996, no qual não havia o reconhecimento da Língua Inglesa no ensino básico público como componente curricular obrigatório, o que contribuiu para que a história brasileira desse ensino, na escola pública, estivesse fadada ao fracasso.

Ainda que esse quadro sombrio aponte para um cenário desanimador no ensino e aprendizagem de língua inglesa na escola pública, não é possível isentá-la da responsabilidade em promover um ensino de qualidade deixando essa função para os cursos livres, restritos somente àqueles que podem pagá-lo.

O Currículo de Língua Estrangeira Moderna do Estado de São Paulo (São Paulo, 2008), em consonância com as Orientações Curriculares para o Ensino Médio (2006), entende que o ensino de Língua Inglesa na escola deve focalizar atividades que promovam o letramento, ou seja, a participação em diferentes práticas sociais que envolvem a leitura e a escrita em Língua Materna e na Língua Estrangeira - Inglês. Isso significa que a aula de língua Inglesa deve criar condições para que o aluno possa participar em atividades que demandam o uso da língua a partir de temáticas relevantes ao seu contexto e de gêneros discursivos variados.

Baseada nos postulados teóricos de Kern (2000), o Currículo de LEM (2008) sugere a variedade e ampliação dos textos trabalhados em sala de aula por meio de práticas de leitura, entremeadas com as habilidades de escrita e de fala. O autor propõe o estudo e a análise de diversos gêneros textuais que contemplem aspectos mais significativos e práticos como, por exemplo, anúncios, cartas, filmes, jornais, textos de revistas, musicas, entrevistas, quadrinhos e outros. Desse modo, 
é possível promover tanto o engajamento em práticas de leitura e escrita mediadas pela oralidade quanto a construção da autonomia necessária para que o aluno desenvolva sua capacidade de aprender a aprender uma língua estrangeira (SÃO PAULO, 2008, p. 43).

Minha experiência como coordenadora pedagógica e professora de Inglês na escola pública estadual, conduz-me à compreensão de que é preciso buscar caminhos possíveis para repensar e ressignificar o ensino dessa língua nesse contexto educacional. É com essa finalidade que este texto tece algumas reflexões e propõe uma atividade para o ensino de LI no ensino básico, com vistas ao letramento e às práticas de leitura subjacente à proposta trazida no Currículo de LEM (SÃO PAULO, 2008).

Após discutir os objetivos de ensino de LI na escola e a visão de leitura do Currículo (2008) ilustro, a partir de uma proposta de atividade para o 1ㅇ ano - Ensino Médio - em Língua Inglesa, inspirada no Caderno do Aluno $(2009)^{1}$, como o ensino por meio de gêneros textuais e pela exploração de recursos linguísticos podem contribuir com as propostas de leitura e letramento.

Assim, podemos vislumbrar que as aulas de Inglês em um contexto público de educação pode ser um espaço para reflexão e autonomia que levem o aluno a compreender seu papel nas práticas sociais em que a língua inglesa é um produto cultural e social valorizado.

\section{REVISÃO BIBLIOGRÁFICA}

\subsection{O ensino de Língua Inglesa na escola pública estadual paulista}

O ensino de língua estrangeira no Brasil passou a ter mais expressão quando a Lei de Diretrizes e Base (LDB) de 1996, artigo 26, parágrafo 5, estabelece a obrigatoriedade do ensino de pelo menos uma língua estrangeira a partir da 5 a série -60 ano - do ensino fundamental. No artigo 36 da seção I da mesma lei, é explicitado que "será incluída uma língua estrangeira moderna, como disciplina obrigatória, escolhida pela comunidade escolar, e uma segunda, em caráter optativo, dentro da disponibilidade da instituição".

Segundo Avelar (2004), ainda que a LDB (1996) trouxesse a obrigatoriedade do ensino de uma língua estrangeira como disciplina obrigatória, ainda havia uma lacuna no trato dos objetivos desse ensino no Brasil. A não explicitação dos objetivos do ensino de LE trazia uma confusão no âmbito das diretrizes curriculares para a educação básica porque o professor de língua estrangeira ficava sem orientação sobre o quê ou como ensinar, recorrendo a aspectos mecânicos do ensino da oralidade - $d r i l l s^{2}$ - o que reforçava o estigma da escola como um lugar onde não se aprende línguas estrangeiras (CELANI, 2005).

\footnotetext{
${ }^{1}$ O Caderno do Aluno faz parte de uma política educacional implantada nas escolas da rede estadual de ensino do Estado de São Paulo com o intuito de centralizar o mesmo conteúdo e a mesma abordagem em todo o estado.

${ }^{2}$ Drills são exercícios orais que tem como objetivo exercitar e fixar usos da língua.
} 
Moita Lopes (1996, p. 127) já apontava essa fragilidade ao afirmar que

embora não se questione a aprendizagem de outras matérias do currículo, as LE são frequentemente apontadas como desnecessárias na formação do aprendiz da escola pública. É comum se ouvirem comentários do tipo: "Já que ninguém aprende LE na escola pública, o melhor que se faz é tirá-las do currículo; "O aluno da escola pública não precisa saber LE"; "Eles não aprendem português quanto mais o inglês.

Com a finalidade de estabelecer uma referência curricular para o ensino de línguas no país, o Ministério da Educação e Cultura - MEC - elaborou os Parâmetros Curriculares Nacionais (PCN, BRASIL, 1998) e trouxe novas propostas para o ensino de línguas estrangeiras, postulando que "o foco na leitura pode ser justificado pela função social das línguas estrangeiras no país e também pelos objetivos realizáveis, tendo em vista as condições existentes" (Brasil, 1998, p. 21).

Embora esse documento enfatize o ensino da leitura nas aulas de língua inglesa, percebemos uma discordância ideológica entre ele e a Lei de Diretrizes e Bases (1996) que traz, no artigo $3^{\circ}$, inciso III, que o ensino será ministrado com base no princípio do "pluralismo de ideias e de concepções pedagógicas" rompendo, assim, com a ideia de um único foco para o ensino de línguas.

Com o avanço das pesquisas na área de Linguística e Linguística Aplicada, a função social da língua estrangeira - Inglês - passa a ter lugar privilegiado, fortalecendo a necessidade de se repensar o ensino e aprendizagem da língua inglesa de modo a expandi-lo e não objetivando uma finalidade específica.

Em 2008, a Secretaria da Educação do estado de São Paulo - SEE/SP - elaborou a Nova Proposta Curricular com o objetivo de melhorar o ensino no estado de São Paulo, por meio de um currículo único, baseando-se, para tanto, em resultados do Sistema de Avaliação da Educação Básica (SAEB/Prova Brasil) e no Exame Nacional do Ensino Médio (ENEM).

Nessa proposta Curricular (2008) que se tornou o Currículo oficial do estado de São Paulo, a SEE/SP ressalta que cumpre seu dever ao "[...] garantir a todos uma base comum de conhecimentos e de competências para que nossas escolas funcionem de fato como uma rede" (SÃO PAULO, 2008, p. 9).

No documento, as orientações para implementar um novo currículo propõem como princípios: a escola que aprende, o currículo como espaço de cultura, as competências como referência, a prioridade para a competência da leitura e da escrita, a articulação das competências para aprender e a articulação com o mundo do trabalho (SÃO PAULO, 2008).

Para a área de Linguagens - Língua Estrangeira Moderna - LEM - (SÃO PAULO, 2008), o Currículo traz questões de ensino e a aprendizagem de línguas que se pautam em alguns aspectos da abordagem comunicativa com uma orientação voltada para o letramento, "propiciando uma visão de ensino de línguas que seja capaz de promover autonomia intelectual e maior capacidade 
de reflexão dos aprendizes, contribuindo decisivamente para a formação cidadã dos educandos" (SÃO PAULO, 2008, p. 42).

Esse documento, que trouxe em sua proposta objetivos que ultrapassam os do PCN (1998) no trato ensino-aprendizagem de língua inglesa, considera o contexto da aprendizagem em seu conjunto. Assim, a habilidade leitora contribui para o desenvolvimento do ensino-aprendizagem que necessita ser desenvolvida juntamente com as outras habilidades - falar, escrever e ouvir.

O Currículo do estado de São Paulo de LEM (2008) traz como princípio que

mais do que objetos de conhecimento, as linguagens são meios para o conhecimento. 0 homem conhece o mundo através de suas linguagens, de seus símbolos. À medida que ele se torna mais competente nas diferentes linguagens, torna-se mais capaz de conhecer a si mesmo, assim como a sua cultura e o mundo em que vive (SÃO PAULO, 2008, p.27).

Essa premissa deixa claro que as aulas de Inglês devem privilegiar atividades que promovam o letramento para favorecer a participação do aluno em diferentes práticas sociais que envolvam a leitura e a escrita na língua - alvo. O Currículo (São Paulo, 2008) ainda esclarece que:

[...] importa construir um conhecimento sistêmico sobre a organização textual e sobre como e quando utilizar a linguagem em situações de comunicação. A consciência linguística e a consciência crítica dos usos da língua estrangeira devem possibilitar o acesso a bens culturais da humanidade (São Paulo, 2008, p.38).

A disciplina língua inglesa, de acordo com o Currículo (São Paulo, 2008), contribui para a construção das práticas de letramento, pois permite ao aluno entrar em contato com outras formas de viver, sentir e expressar-se, priorizando contextos autênticos de comunicação.

De acordo com Kern (2000), que é um dos teóricos que embasa as propostas do Currículo (São Paulo, 2008), a utilização de diversos gêneros textuais pode fazer com que os aprendizes reflitam acerca do seu próprio processo de leitura. Além disso, essa prática leva o aluno a compreender como sua interpretação é influenciada por suposições culturais específicas, crenças, atitudes e valores. É necessário que o aprendiz tenha consciência de que a leitura é um ato recursivo no qual a sua interpretação pode ser repensada, tendo em vista novos conhecimentos e novas experiências. Quanto mais o leitor for capaz de reformular o sentido e o significado do texto manipulando o contexto e a língua, maior será sua habilidade em lidar com práticas sociais diversas.

\subsection{A Leitura e os Letramentos na perspectiva do Currículo de LEM}

O Currículo de LEM (São Paulo, 2008), baseia-se teoricamente nos postulados de Kern (2000), que recomendam o aprendizado por meio de atividades que levem o aluno a compreender 
as conexões entre sua vivência cotidiana e seus estudos, a fim de aprimorar sua formação pessoal e intelectual para melhor inserção nas práticas sociais e culturais. Isso constitui o processo de letramento, por meio do qual o sujeito se torna um cidadão atuante, crítico e reflexivo para ser capaz de fazer uso da leitura e da escrita de forma autônoma no meio em que vive.

Celani (2005) concorda com essa concepção ao afirmar que os alunos devem participar do processo de ensino e aprendizagem não como meros receptores de informações, mas como seres conscientes, críticos e participantes ativos desse processo.

A proposta de letramento Kern (2000) sugere que os professores trabalhem com textos de gêneros diversos em sala de aula para oportunizar ao aluno a análise de aspectos significativos e práticos que são contemplados nos anúncios, nas cartas, nos filmes, nos jornais, nos vídeos, nas músicas, nos quadrinhos e outros.

O ensino com base nessa proposta de letramento contempla situações que levam à leitura reflexiva na qual os aprendizes devem lidar com as mais diversas situações para que se prepare para lidar com as contrariedades e incertezas a que estamos sujeitos cotidianamente.

Na mesma direção, Luke e Freebody (2000) defendem que ler envolve decodificar, participar, usar e analisar o texto para inserir-se de modo pleno e participativo na vida em sociedade. Como decodificador, o leitor precisa acionar seu conhecimento relativo ao mecanismo do texto escrito, como a combinação de letras, relação entre o signo linguístico e seu som (significante e significado) e a noção de vocabulário. Como participante, ele precisa relacionar as informações do texto com o seu conhecimento de mundo e, como usuário e analista, ele precisa posicionar-se criticamente conforme a expectativa gerada pelo texto que está lendo.

A conscientização crítica promovida linguagem faz parte do aprendizado do aluno nesse contexto. Figueiredo (2000) aborda que a conscientização no âmbito da leitura tem o objetivo integrar o aluno a uma sociedade já constituída, subordinando-se ela. Por outro lado, a conscientização defendida pelo Currículo de LEM (São Paulo, 2008), tem como função integrar e emancipar o indivíduo, levando-o não apenas a atuar na sociedade, como também modificá-la, quando necessário.

Assim, como analista, o leitor deverá ser crítico em relação à ideologia subjacente ao texto, lendo as entrelinhas para reconhecer o que está implícito e pressuposto, tendo em mente que qualquer texto traz um ponto de vista e que autor e leitor tomam posições em relação ao que leem/escrevem.

As etapas de decodificar, participar, usar e analisar acontecem de forma integrada e concomitante no decorrer da leitura e o conhecimento necessário para desempenhar essas etapas de forma integradas são adquiridas pelas práticas de leitura cotidianas em sala de aula e em situações informais do dia a dia.

A formação de um leitor proficiente é realizada por intermédio das práticas de todas essas etapas desde o início do ensino de Língua Estrangeira e Língua Materna. Nesse sentido, as perguntas de leitura, desde o nível básico, devem contemplar todas as ações, refletindo a leitura que normalmente fazemos de diferentes textos. Assim, nas OCEM $(2006$, p.98) 
procura -se desenvolver um leitor como aquele que entende que aquilo que lê é uma representação textual, como aquele que, diante do que lê, assume uma posição ou relação epistemológica no que concerne a valores, ideologias, discursos, visão de mundo. Com esse pressuposto, ensinar requer compreender esses conceitos e compreender: I - como as pessoas utilizam a leitura (e para quê) em sua vida ou no cotidiano; II - que a leitura tem a ver com a distribuição de conhecimento e poder numa sociedade; III- que o tipo e desenvolvimento de leitura que se realiza resulta no desenvolvimento de um tipo de leitor.

Kern (2000), em uma direção complementar e consonante com as postulações sobre leitura tecidas pelas OCEM (2006) afirma que leitores não são indivíduos homogêneos e, por isso, a leitura não pode ser considerada como um processo universal e uniforme, mas sim uma prática individual contextualmente apropriada. Ainda em Kern (2000), isso revela que os leitores não devem interpretar e ler livremente os textos conforme o que lhes convém, pois existem pressupostos que precisam ser considerados no ato da leitura para que o leitor tenha sua participação legitimada em práticas sociais.

O autor assevera que o trabalho com gêneros textuais variados pode levar os alunos à reflexão do seu próprio ato de leitura, possibilitando a percepção de como sua interpretação pode ser manipulada pelas mídias, crenças e valores de determinada comunidade.

Kern (2000) considera, ainda, a leitura como um plano significativo em que os leitores são encorajados a se posicionarem sobre as ideias advindas do texto. O Currículo de São Paulo (2008, p.44) reafirma essa visão ao postular que

já no Ensino Médio, os alunos, mais maduros afetiva, cognitiva e metacognitivamente devem ter a oportunidade de utilizar e aprofundar, em situações que propiciem o exercício da reflexão crítica, conhecimentos construídos anteriormente.

Tais posturas podem ser desenvolvidas mediante o trabalho em sala de aula com gêneros textuais diversos. Nesse sentido, Bakhtin (2003) aponta que estamos expostos aos gêneros da mesma forma que estamos expostos à língua materna, ou seja, as formas da língua e os gêneros são resultados de uma co-construção social, isto é, das experiências que temos com diferentes situações de uso da linguagem ao longo de nossas vidas".

Dessa forma, é função da escola criar oportunidades de leitura e escrita em sala de aula com os gêneros textuais, planejar atividades com finalidades diversas e intencionais para atingir objetivos específicos de aprendizagem, atentando para o fato de que para cada uso de linguagem é importante planejar atividades que visem a reconhecer a situação de comunicação: quem fala, para quem fala, em que contexto, em que suporte e com que objetivo. 


\section{METODOLOGIA}

3.1 A escolha e o planejamento da atividade e do material didático para as aulas de língua inglesa

A seleção dessa atividade e desse material devem-se aos seguintes motivos: o tema que promove a discussão sobre a violência entre os adolescentes e seus motivos, expondo diferentes opiniões; o gênero textual/discursivo relevante para promover o senso crítico, levando o aluno a posicionar-se em relação à função persuasiva do texto); os textos curtos que oferecem a possibilidade de trabalhar recursos linguísticos básicos de forma contextualizada.

Nesta seção, traço critérios para a elaboração de atividades de Língua Inglesa com vistas à proposta de letramento e leitura do Currículo de LEM (São PAULO, 2008). Para tanto, baseio-me em Bortolini (2006) que propõe alguns critérios e materiais didáticos para o ensino de língua estrangeira.

É importante destacar que esses critérios coadunam com as concepções de ensino de línguas de cada professor e podem ser modificados e adaptados de acordo com o contexto de ensinoaprendizagem no qual atua.

Considero, ainda, os aspectos sociais e culturais, bem como os conteúdos de Língua Inglesa previstos para a série selecionada. Assim, destaco como importante:

a) Elencar as situações de comunicação que fazem parte do tema a ser estudado na série/ ano que a aula será realizada. Se, por exemplo, o tema for Meio Ambiente, é importante listar textos diversos relacionados a temas como a água, florestas, animais, separação do lixo, clima e outros. Os gêneros podem ser formulários informativos, campanhas de proteção ao meio ambiente, chamadas para trabalho voluntário, artigos de jornal, em que as perguntas para a prática de leitura desses textos levem em conta a natureza dialógica do uso da língua nas diferentes situações de comunicação, tendo em vista os interlocutores, os propósitos de comunicação, o canal utilizado, o contexto de produção e de recepção do texto;

b) A partir dos gêneros e textos selecionados, é importante pensar sobre quais as habilidades que deverão ser privilegiadas, embora as habilidades da língua aconteçam de forma relacionada e integrada;

c) Decidir quais as funções linguísticas que terão maior foco de aprendizagem, por exemplo, se o texto planejado para a aula é uma propaganda, a função de convencer e persuadir o leitor/interlocutor estará em foco e, para isso, o uso de determinados recursos linguísticos como o uso de verbos imperativo e de falas com depoimentos pode ser utilizado, como: Lowpricesthisweek, do not miss promotion, buynow!;

d) Elaborar e/ou adaptar as atividades que considerem quais os conhecimentos prévios que o aluno precisa ter para conseguir ler as informações gerais do texto, compreender o vocabulário, fazer conexões entre uma informação e outra e inferir significados. Ter em mente as seguintes premissas: quais conhecimentos serão ativados com o estudo desse texto? "É importante acompanhar 
criticamente esse processo e lembrar que linguagem, cultura e conhecimento não são estanques, mas sim conjuntos abertos e dinâmicos" (OCEM, 2006, p. 110);

e) Oportunizar os alunos a usar língua em vários contextos, encorajando-os a interagir com os colegas da sala de aula por meio das atividades em duplas ou em grupos e com outros membros da comunidade. O papel do professor deve ser o de mediar a aprendizagem, auxiliando o aluno em suas dúvidas e dando sentido às atividades realizadas em sala de aula.

f) Analisar se a atividade proposta privilegia o uso dos recursos gramaticais e linguísticos de forma contextualizada para que o foco esteja no sentido e não somente na forma. Para isso, a atividade proposta deve levar o aluno a refletir se os recursos linguísticos do texto como palavras, expressões, entonação, pronúncia, etc. atribuem sentido ao texto e que recursos linguísticos seriam necessários para adequar o texto a outros propósitos de comunicação;

g) Avaliar as atividades. Para avaliar a atividade realizada em sala de aula, o professor deve tentar responder as perguntas: Os objetivos foram atingidos ou devem ser retomados? Quais aspectos devem ser levados em conta na avaliação do aluno, do professor e da aula? De que maneira? Como redirecionar as atividades dessa aula? O que foi aprendido? O que precisa ser retomado? Por que? O que os alunos acharam dessa atividade?

O professor deve atentar-se para questões que podem influenciar nos objetivos para a leitura, como: o texto é longo? como lidar com a extensão do texto? que outras informações, conexões e pressupostos ajudam na compreensão? como as perguntas podem contribuir com o aluno/leitor para alcançar esses objetivos? como as ideias do texto se relacionam com a vida real dos alunos? quais as informações, perspectivas e ideias novas o texto traz e que podem ser úteis à formação pessoal e cognitiva do aluno?

Dessa maneira, os critérios elencados apontam o que é importante para a condução de um plano de aula de leitura em língua inglesa com vistas a uma proposta de letramento que privilegie os gêneros textuais e suas formas de uso.

3.2 Uma atividade para aulas de língua inglesa que privilegia a leitura e o letramento

Apresento, a seguir, uma proposta de atividades para aulas de Inglês, no Ensino Médio, utilizando o gênero Cartas ao editor - Letterstoeditors -, cujos objetivos são desenvolver o processo de leitura e alguns aspectos linguísticos e gramaticais com vistas ao letramento.

A fim de facilitar a visualização, elaborei a proposta em forma de quadro, contendo as Atividades, os Objetivos e a Metodologia, descrevendo cada um desses passos.

A seleção da atividade e do material devem-se aos seguintes motivos: o tema pode instigar a discussão sobre a violência entre os adolescentes e suas possíveis causas, levando o aluno a refletir sobre sua opinião e os textos da atividade oferecem a possibilidade de trabalhar recursos linguísticos de forma contextualizada. 
Quadro 1: Preparação das atividades

Preparação - Informações preliminares

Público-alvo: Alunos do 1 o ano do Ensino Médio de uma escola pública estadual paulista.

Número de alunos na sala: 25

Duração da atividade: 2 aulas

Fonte: autoral

Contextualizando as Lettersto editor:

Os dois textos apresentados para motivar o desenvolvimento das atividades propostas aqui, foram retirados do Caderno do Aluno (vol. 1,10 ano EM). Para contextualizá-los, apresento a seguir o enunciado (traduzido) constante no Caderno do Aluno que antecede esses textos:

"Mulheres: volte para onde você pertence", publicado na seção Opinião de um jornal, no qual o colunista defendeu firmemente seu argumento de que a violência entre adolescentes é um problema doméstico e a solução para isso somente será alcançado se as mulheres assumirem o papel de mães e cuidadoras devendo ficar em casa para educar seus filhos em vez de competir com os homens no mercado de trabalho.

Os dois textos seguintes são as Lettersto editor postadas por leitores do referido jornal:

\section{To the editor}

I want to congratulate you for publishing such an insightful article. It is time we went back to traditional values, and it seems that, on account of what is "politically correct", people have been hiding the truth about what has been making our society fall apart. I totally agree with every single line I read and I want to say it loud and clear.

Johanne Sushbeck, 40

\section{To the editor}

When I read the article "Women: go back to where you belong", I was totally shocked.

In a society which is struggling hard to guarantee and protect the rights not only of women but also of several minority groups - or maybe I should call them priority groups -, it is outrageous to find people who still think like this. It was a shame to see that all the gains in the field of social democracy and equity were totally disregarded by the author.

Kean Smashfield, 53 


\begin{tabular}{|c|c|c|}
\hline Atividades & Objetivos & Metodologia \\
\hline $\begin{array}{l}\text { 1a: Sondagem dos conhecimentos dos } \\
\text { alunos: } \\
\text { a) Você costuma ler jornais? } \\
\text { b) você já leu a seção: "Carta para o leitor" } \\
\text { ou "Carta para o editor"? } \\
\text { c) você sabe qual é a função desse tipo de } \\
\text { texto? } \\
\text { d) Quem escreve esse tipo de texto? Por } \\
\text { que? } \\
\text { f) Quem pode ser influenciado por esse tipo } \\
\text { de texto? Como se dá essa influência? }\end{array}$ & $\begin{array}{lr}\text { Sondar } & \text { o } \\
\text { conhecimento dos } \\
\text { alunos sobre o tema } \\
\text { estudador as } \\
\text { respostas dos alunos } \\
\text { poderão ser } \\
\text { contrastadas mais } \\
\text { adiante com as do } \\
\text { texto. }\end{array}$ & $\begin{array}{l}\text { Antes de iniciar a atividade } \\
\text { de leitura, é importante } \\
\text { ativar o conhecimento dos } \\
\text { alunos com relação ao } \\
\text { gênero textual estudado a } \\
\text { fim de levar o aluno a } \\
\text { analisar o texto de forma } \\
\text { mais intencional. Se o aluno } \\
\text { não tiver esse } \\
\text { conhecimento, cabe ao } \\
\text { professor ajudar os alunos a } \\
\text { reconhecerem o gênero } \\
\text { para preparar leitura. }\end{array}$ \\
\hline $\begin{array}{l}\text { 2a: Preparação para a leitura } \\
\text { Apresentação dos dois textos - Lettersto } \\
\text { editor-à sala } \\
\text { a) Olhando para o texto, a que você } \\
\text { relaciona as palavras: } \\
\text { VIOLENCE; TEENAGER; DOMESTIC } \\
\text { PROBLEM. }\end{array}$ & $\begin{array}{l}\text { Promover uma } \\
\text { primeira inserção do } \\
\text { aluno com o texto, de } \\
\text { modo que ele } \\
\text { reconheça o gênero } \\
\text { textual, bem como } \\
\text { algumas palavras } \\
\text { relacionadas ao } \\
\text { tema. }\end{array}$ & $\begin{array}{l}\text { O professor pode pedir para } \\
\text { que os alunos façam uma } \\
\text { leitura rápida (skimmimg), } \\
\text { orientando-os a "passar os } \\
\text { olhos pelo } \\
\text { texto"eprestando atenção } \\
\text { ao layout do texto, ao título } \\
\text { e aos cognatos. }\end{array}$ \\
\hline $\begin{array}{l}\text { 3a:Leitura } \\
\text { Em duplas. Com base na leitura rápida dos } \\
\text { dois textos, respondam: a) Quem escreveu } \\
\text { os textos? } \\
\text { b) A quem se destina os textos? } \\
\text { c) Quais são as semelhanças e diferenças } \\
\text { entre eles? } \\
\text { Discuta suas respostas com as outras } \\
\text { duplas. }\end{array}$ & 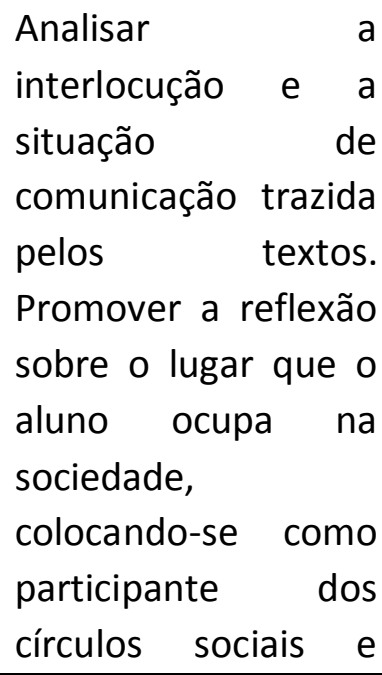 & $\begin{array}{l}\text { Essa atividade pode ser } \\
\text { realizada em duplas a fim de } \\
\text { incentivar a interação à } \\
\text { medida que os pares trocam } \\
\text { opiniões com o colega, } \\
\text { ouvindo-o e sendo ouvido. }\end{array}$ \\
\hline
\end{tabular}




\begin{tabular}{|c|c|c|}
\hline & $\begin{array}{l}\text { culturais que está } \\
\text { analisando. }\end{array}$ & \\
\hline $\begin{array}{l}\text { 4a. Leitura } \\
\text { a) Marque no texto as palavras que você } \\
\text { conhece. } \\
\text { b) Relacione as palavras ou expressões } \\
\text { abaixo à tradução, levando em } \\
\text { consideração o contexto. } \\
\text { tradicional values, politically correct, our } \\
\text { society, fall apart, totally agree, women: go } \\
\text { back to where you belong", minority groups, } \\
\text { priority groups, social democracy, } \\
\text { disregarded by the author. } \\
\text { Em que essas palavras e expressões } \\
\text { contribuíram para a compreensão do texto? } \\
\text { Converse sobre suas respostas com outras } \\
\text { duplas. }\end{array}$ & $\begin{array}{lr}\text { Ensinar alguns } \\
\text { recursos linguísticos } \\
\text { fundamentais para a } \\
\text { compreensão do } \\
\text { texto. }\end{array}$ & $\begin{array}{l}\text { O professor pode auxiliar o } \\
\text { processo de leitura com os } \\
\text { alunos ajudando-os a } \\
\text { reconhecer algumas } \\
\text { palavras e ensinando outras } \\
\text { novas, fazendo algumas } \\
\text { conexões entre elas e a } \\
\text { mensagem do texto. }\end{array}$ \\
\hline $\begin{array}{l}\text { 5a: Leitura. Discuta em duplas: } \\
\text { Text 1and text 2: } \\
\text { Who supports the ideas presented by the } \\
\text { authors? Who is against them? Kean } \\
\text { Smashfield suggests an alternative term for } \\
\text { minority groups. What is it? } \\
\text { Johanne Sushbeck calls for a return to } \\
\text { traditional values. What do you think } \\
\text { these values are? }\end{array}$ & $\begin{array}{lr}\text { Aprofundar } & \text { a } \\
\text { compreensão das } \\
\text { ideias tecidas pelos } \\
\text { autores e avaliar } & \text { os } \\
\text { argumentos } & \text { e } \\
\text { sugestões tecidas. }\end{array}$ & $\begin{array}{l}\text { A partir da atividade } \\
\text { anterior, em que os alunos } \\
\text { trabalharam aspectos do } \\
\text { vocabulário para } \\
\text { compreender o texto, o } \\
\text { professor pode auxiliar as } \\
\text { duplas à medida que } \\
\text { relaciona os dois textos, } \\
\text { elencando os pontos em } \\
\text { comum e os divergentes. } \\
\text { Nessa atividade, as } \\
\text { reflexões, o senso crítico e } \\
\text { as opiniões da sala podem } \\
\text { ser discutidas. }\end{array}$ \\
\hline
\end{tabular}




\begin{tabular}{|c|c|c|}
\hline $\begin{array}{l}\text { 6a: Usando as expressões para construir } \\
\text { opiniões. } \\
\text { I'd say the exact opposite. } \\
\text { I couldn't agree with you more. } \\
\text { I don't think so. } \\
\text { That's so true. } \\
\text { You're absolutely right. } \\
\text { That's exactly what I think. } \\
\text { I agree with you100 percent. } \\
\text { I have a different opinion } \\
\text { Use as expressões acima e faça um quadro } \\
\text { em seu caderno para tecer as ideias com as } \\
\text { quais discorda ou concorda. Antes, porém, } \\
\text { selecione as que se relacionam com } \\
\text { "discordo" e as que se relacionam com } \\
\text { "concordo". }\end{array}$ & $\begin{array}{lr}\text { Compreender } & \text { a } \\
\text { função de algumas } \\
\text { estruturas } & \\
\text { linguísticas } & \text { na } \\
\text { situação } & \text { de } \\
\text { comunicação } & \\
\text { focalizada } & \end{array}$ & $\begin{array}{l}\text { Essas expressões podem ser } \\
\text { revisadas, com o auxílio do } \\
\text { professor, sempre com } \\
\text { vistas ao vocabulário já } \\
\text { estudado. } \\
\text { Pedir para que os alunos } \\
\text { escrevam as ideias com as } \\
\text { quais discorda ou concorda, } \\
\text { de acordo com o enunciado } \\
\text { e as cartas ao editor. } \\
\text { Pode acontecer de os } \\
\text { alunos terem outras } \\
\text { opiniões que extrapolem a } \\
\text { dos textos estudados. Nesse } \\
\text { momento é importante que } \\
\text { o professor auxilie os alunos } \\
\text { na produção de sentenças. }\end{array}$ \\
\hline $\begin{array}{l}\text { 7a: Usando inglês para conhecer o colega. } \\
\text { O professor lança o questionamento: Do } \\
\text { youagreeordisagreewitheachopinion? } \\
\text { Em seguida, o professor pode demonstrar } \\
\text { sugestões para os alunos tecerem suas } \\
\text { respostas: } \\
\text { "In my opinion, men and women } \\
\text { have similar social roles and should have } \\
\text { the same rights". }\end{array}$ & $\begin{array}{l}\text { Provocar interação } \\
\text { entre os pares, } \\
\text { trabalhando as } \\
\text { diferentes opiniões. }\end{array}$ & $\begin{array}{l}\text { O professor pode sugerir } \\
\text { algumas reflexões e } \\
\text { discussões entre as duplas e } \\
\text { as duplas e a sala para } \\
\text { levantar algumas opiniões } \\
\text { sobre o que pensam sobre o } \\
\text { tema. Nesse momento, } \\
\text { pode fazer um breve } \\
\text { traçado histórico sobre as } \\
\text { das mulheres lutas por } \\
\text { direitos, sobre o papel que } \\
\text { desempenham na } \\
\text { sociedade e como o } \\
\text { preconceito com relação a } \\
\text { elas ainda é forte nos dias } \\
\text { atuais. } \\
\text { As expressões linguísticas } \\
\text { podem ser grafadas na } \\
\text { lousa e explicadas aos } \\
\text { alunos. }\end{array}$ \\
\hline 8a Autoavaliação & $\begin{array}{l}\text { Criar } \\
\text { oportunidade }\end{array}$ & $\begin{array}{l}\text { O professor pode pedir para } \\
\text { que os alunos, }\end{array}$ \\
\hline
\end{tabular}




\begin{tabular}{|c|c|c|}
\hline $\begin{array}{l}\text { Faça uma autorreflexão e responda em } \\
\text { Português: } \\
\text { a) O que aprendi com as mensagens } \\
\text { trazidas por esses textos? } \\
\text { b) Como essa atividade pude melhorar } \\
\text { minha leitura em Inglês? } \\
\text { c)Esse tema me levou a refletir sobre ele de } \\
\text { maneira crítica? Como? } \\
\text { d)As atividades propostas foram } \\
\text { importantes em que medida? } \\
\text { e) Esse tema é relevante e deve ser levado } \\
\text { para discussão em outras aulas? }\end{array}$ & $\begin{array}{l}\text { autorreflexão sobre o } \\
\text { que foi aprendido e } \\
\text { sobre } \\
\text { participação sua } \\
\text { aprendizagem } \\
\text { sala de aula. }\end{array}$ & $\begin{array}{l}\text { individualmente, reflitam } \\
\text { sobre o ciclo de atividades } \\
\text { realizado. } \\
\text { É importante que o } \\
\text { professor crie momentos de } \\
\text { socialização entre ele e a } \\
\text { sala para, com isso, avaliar o } \\
\text { aprendizado dos alunos e a } \\
\text { sua própria metodologia. } \\
\text { Esse feedback é } \\
\text { fundamental para que as } \\
\text { práticas em sala de aula } \\
\text { sejam aprimoradas e } \\
\text { construídas com base nas } \\
\text { reflexões das partes } \\
\text { envolvidas nesse processo- } \\
\text { alunos e professor. }\end{array}$ \\
\hline
\end{tabular}

\section{DISCUSSÃO}

Ao propor esse ciclo de atividades em aulas de Língua Inglesa com foco nas práticas de leitura na perspectiva do letramento, penso em contribuir com o ensino dessa língua de modo que ele possa ganhar mais sentido ao se integrar com função social da escola, que é o de criar condições para o aluno desenvolver suas potencialidades cognitivas e afetivas, tornando-se um cidadão engajado na sociedade em que vive.

As atividades foram apresentadas no quadro de forma separada, porém elas são didaticamente entrelaçadas e se conectam umas às outras na medida em que para realizar uma delas, o aluno pode/deve retornar a anterior. Ainda que essas atividades componham uma proposta com objetivos e público-alvo definidos, elas podem ser modificadas, adaptadas e complementadas de acordo com a intenção do professor, visto que fatores como imprevisibilidade, incertezas e mudanças internas e externas podem permear o contexto da sala de aula.

Com vistas a contemplar algumas formas de letramento (Kern,2000), as atividades propostas concebem a leitura como processo discursivo no qual estão claros os papéis dos sujeitos produtores de sentido - autor e leitor - em que ambos são "sócios, historicamente determinados e ideologicamente constituídos cujo momento histórico social determina o comportamento, as atitudes, a linguagem de um e de outro e a própria configuração de sentidos". (CORACINI, 1995, p.15)

Assim, essa proposta que traz o gênero "Carta ao editor", pode fazer com que os alunos reflitam sobre seu próprio processo de leitura ao mesmo tempo que compreendem como sua interpretação é/não é influenciada por valores, crenças, preconceitos e atitudes de outro, oportunizando-o tecer argumentos contrários ou favoráveis acerca da mensagem que o texto manifesta. 
Em termos práticos, podemos vislumbrar na proposta, as fases de sondagem que envolve a 1a atividade na qual o professor pode fazer questionamentos à sala antes de propor a atividade da aula. Nessa primeira atividade, os questionamentos do professor conduzem o aluno a uma inserção e engajamento na proposta da aula, levando-o a pensar criticamente sobre o texto.

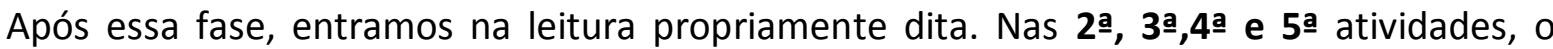
desenvolvimento da leitura leva em conta cada objetivo na qual mediação do professor é fundamental para auxiliar o aluno a reconhecer a situação de comunicação, o papel dos interlocutores, a mensagem trazida por meio do gênero trabalho e a importância dos recursos linguísticos na constituição do texto como produtor de sentido.

O uso das expressões linguísticas específicas auxilia o aluno a compreender sua relação com o sentido da mensagem do texto, sobretudo quando esse exercício é realizado em duplas ou entre as duplas (7aa atividade)

Para finalizar esse ciclo de atividades com vistas a aprimorar a elaboração dos próximos, a fase da autoavaliação é fundamental. Ela pode ser realizada em forma de socialização entre os alunos e professor, motivada pelas perguntas que provocam a autoavaliação das partes envolvidas. Essa ação é uma medida interessante tanto para o aluno tomar consciência de seu percurso de aprendizagem e se responsabilizar pelo próprio avanço como para professor refletir sobre a ação de planejar as intervenções em sala de aula.

\section{CONCLUSÃO}

O ensino de língua inglesa nas escolas públicas estaduais tem vivenciado algumas mudanças decorrentes de outras mudanças que afetam a sociedade, a política, a cultura, os valores e a formação dos jovens. Devido a esses e outros fatores, o ensino da leitura e da escrita precisam ser repensados e ressignificados para ir além da decodificação de palavras e de uma interpretação superficial do texto para atender a práticas sociais fundamentais que levem o educando a interagir de forma plena e responsável com o mundo que o cerca.

A escola, como a maior agência de letramento da sociedade, tem a função, na figura do professor, de oportunizar aos alunos um ambiente em que o letramento faça parte de seu cotidiano. Assim, as aulas de leitura em língua inglesa, por exemplo, têm muito a contribuir com uma prática de letramento quando oportuniza o trabalho com gêneros textuais diversos de modo que o aluno compreenda que, dependendo da finalidade do gênero estudado, o texto apresenta diferentes funções sociais.

O ensino de línguas baseado nos pressupostos de Leitura e Letramento (Kern, 2000) tem como proposta articular os conteúdos da aula com as vivências cotidianas do aluno para formar cidadãos mais participativos na sociedade. Isso requer criticidade do professor para que tenha consciência da necessidade de relacionar teoria e prática, reflexão e ação, objetivos de ensino com o contexto de ensino, enfatizando o papel do leitor e do escritor nas atividades que propõe. 
Nesse sentido, um dos princípios norteadores do Currículo de LEM (SÃO PAULO, 2008) corrobora ao afirmar que

a escola deve propiciar uma visão de ensino de línguas que seja capaz de promover autonomia intelectual e maior capacidade de reflexão dos aprendizes, contribuindo decisivamente para a formação cidadã dos educandos (SÃO PAULO, 2008, p. 42).

Dessa forma, o importante nas aulas de Língua Inglesa e em Língua Materna é criar oportunidades para a leitura e a escrita em que os participantes - aluno e professor possam engajarse em práticas que os tornem cada vez mais apto em analisar o que está lendo, atentando-se, inclusive para as estruturas linguísticas que se encadeiam no texto.

O ciclo de atividades apresentadas neste estudo não teve um objetivo explícito para ser desenvolvido de forma inter ou transdisciplinar, mas vislumbra conexões com outras disciplinas da escola, cabendo ao professor-executor da proposta promover projetos a fim de construir formas de ensino que contribuam para o letramento e para a integração dos conhecimentos nos diferentes conteúdos curriculares que, direta ou indiretamente permeiam e interferem na formação pessoal e cognitiva do aluno.

\section{REFERÊNCIAS}

AVELAR, F. J. S. (2004). Visões e ações de uma professora em serviço: reflexões sobre a construção do ensino de leitura em língua estrangeira. 2004. 178 f. Dissertação de Mestrado, Universidade Federal de Uberlândia, Uberlândia.

BAKHTIN, M. (2003). Estética da criação verbal. São Paulo, Martins Fontes.

BORTOLINI, L.S. (2006). Os conceitos de uso de língua, identidade e aprendizagem subjacentes ao material didático para o ensino de português. Monografia (Licenciatura em Letras) - Instituto de Letras, Universidade Federal do Rio Grande do Sul, Porto Alegre.

BRASIL. (1998). Parâmetros Curriculares Nacionais - terceiro e quarto ciclos do ensino fundamental: Língua Estrangeira. Brasília: Ministério da Educação e do Desporto.

CELANI, M. A. A; DEYES, A.F; HOLMES, J.L; SCOTT, M. R. (2005). ESP in Brazil: 25 yearsof Evolution andReflection. Campinas, SP: Mercado de Letras, Educ.

CORACINI, M. J. R. F. (Org.). (1995). O jogo discursivo na aula de leitura: língua materna e língua estrangeira. Campinas, SP: Pontes.

COX, M. I. P.; ASSIS-PETERSON, A. A. (2008). O drama do ensino de inglês na escola pública brasileira. In: Assis-Peterson, A. A. (org.). Línguas estrangeiras: para além do método. Cuiabá: EdUFMT, p. 19-54 
KERN, R. (2000). Literacy and language teaching. Oxford: Oxford University Press.

LEI DE DIRETRIZES E BASES. (1996). Ministério da Educação e do Desporto. Brasília: MEC.

LUKE, A; FREEBODY, P. (2000). Shaping the social practices of reading. In: S. MUSPRATT; A. LUKE; P. FREEBODY (orgs.), Constructing critical literacies. St. Leonards, Austrália, Allen \&Unwin, p. 185227; FIGUEIREDO, C. A. Leitura Crítica: Mas isso faz parte do ensino de leitura? - Subsídios para a Formação de Professores de Língua Estrangeira, 2000. 255 f. Tese de Doutorado. UNICAMP, Campinas.

MOITA LOPES, L. P. (1996). Oficina de Linguística aplicada. Campinas: Mercado de Letras. 190 p

ORIENTAÇÕES CURRICULARES PARA O ENSINO MÉDIO (OCEM). (2006). Linguagens, códigos e suas tecnologias/Secretaria de Educação Básica. Brasília, Ministério da Educação, Secretaria de Educação Básica. Conhecimentos de línguas estrangeiras, vol. 1, p. 85-124

SÃO PAULO. (2008). Secretaria de Estado da Educação. Nova Proposta Curricular de LEM. São Paulo: SEE.

SÃO PAULO (Estado). (2009). Secretaria da Educação. Caderno do Aluno. Inglês ensino médio 1o ano, vol. 1 - São Paulo: SE/CENP. 